\title{
COMPLICACIONES APENDICULARES
}

\section{CO-RELATOR Dr, ALFREDO GANTZ}

Al hablar de las complicationes, solamente haré men. ción de los casos observados en nuestro Servicio, que como veremos, a pesar del alto número de operados $(1,981)$; son raras. Pero esta rareza de las complicaciones en el niño,. parecen darle a este cuadro una gravedad mayor que la que encierran para el adulto. Comparándolas, a su vez, en los diferentes años, se puede apreciar el enorme adelanto que significó para la cirugia el descubrimiento de las sulfas y penicilina, el empleo más metódico de las transfusiones, ya sea de sangre o plasma, y no mucho menos el empleo de la sonda Miller Abbott, o mejor dicho, el vaciamiento gástrico e intestinal.

El éxito post-opetatorio va íntimamente ligado a la preparación del enfermo, a la técnica quirúrgica empleada y a la anestesia. E1 primero de los factores exige la colaboración indispensable del pediatra, con el objeto que el enfermo llegue a la mesa de operación, con el máximo de garantías de éxito. Sólo así pođremos evitar complicaciones que en realidad no son otra cosa que fracasos.

Es lógico que aquellos casos que necesitan una intervención inmediata, deben recibir de preferencia, durante el acto operatorio o luego después de él, los tratamientos complementarios incuispensables.

El ideal es opetar, previo teposo fisiológico del tracto intestinal, suprimiendo desde la nocbe anterior, por lo menos, la ingestión de alimentos y mesurar los líquidos.

E1 caidado post-operatorio tiene tanta importancia como el tratamiento anterior a la operación; y para evitar las complicaciones es menester controlar personalmente a estos enfermos. No basta la carva térmica para seguir la evolución de esta enfermedad, es indispensable la palpación abdominal prolija. Ella, como veremos más adelante, es la campana de alarma de algo grave que se aproxima, de algo que visto a tiempo puede ser evitado, y para lo cual las horas corridas tienen enorme valor pronóstico.

En forma esquemática, nuestras complicaciones pueden resumirse en las siguientes: 


\section{CUADRO N* 1}

\section{8 abscesos de la pared.}

4 hemorragias intraperitoneales post-operatorias.

184 peritonitis.

3 plásticas.

1 absceso subfrénico.

3 obstracciones mecánicas por atherencias.

3 volvulus.

8 dilataciones gástricas e intestinales.

4 ileos paralíticos.

4 neumonias.

8 fístulas estercoráceas.

Respecto a los abscesos de la pared, éstos han ido todos profundos y se han observado como complicaciones de prit tonitis operadas. Nos ha llamado la atención la poca defersa de la pared del niño, y aun hasta podriamos decir. 'a selectividar: te los agentes piógenos por ella, que a pesar de las sulfas y penicilina local y general no logra evirar su formación. La evolución de ellas es benigna, obligando al enfermo sćlo a guardar mayor teposo. En aquellos cases $\in \mathbf{n}$ que se ha risado hilo para el plano músculo-aponeurótico, es indispensable alejar dichos puntos, pues son ellos los agentes causales de supuraciones rebeldes con tendencia a la cronicidad.

Las hemorragias post-operatorias fueron ocasiunadas en 3 casos por vacos del meso y su causa ha sido justamente el deslizamiento de uno de ellos, generalmente el posterior, bajo la pinza de Kocher, cuando se secciona el meso. Esta complicación la consideramos evitable, practicando siempre 1a doble ligadura del meso (con hilo) y del apéndice (base con catgut) en un solo tiempo. Sólo después de este acto debe cortarse el meso y examinar siempre el muñón, tratando de reducirlo, para evitar que la tracción que se ejerce sobre el apéndice por la pinza Kocher, colocada en el vértice, obstruya un vaso que libremente sangraría. Tuvimos un caso mortal. Desde que empleamos esta técnica no hemos vuelto a observar hemoperitoneos.

Las peritonitis, generalizadas, en sa mayoría, corres pondian a cuadros peritoneales que ya existian durante la operación y su evolución con el uso de la sulfa y penícilina intraperitoneal $y$ general, ba mejorado enormemente en cuanto a pronóstico. Aun-más, son contados los casos en que el cirujano, al enfrentar este cuadro, hoy día deja drenaje. 
Las localizadas se presentaron coma complicaciones de abscesos apendiculares, en las cuales muchas veces es difícil la extitpación completa de él, el cual, englobado por el epiplón, constituye una gran masa carnificada. Desde que practicamos la resección parcial o total del epiplón, su frecuencia ha disminuido. Dos peritonitis tuvieron su origen en un absceso del muñón, el cual, por habet quedado algo largo, seguramente mal invaginado y haber cedido la ligadura, permitió el vaciamiento de su contenido a la cavidad abdominal. Para evitarlo, usamos desde entonces hilo fino para la gareta y catgut para la ligadura del muñón apendicular, ya que el catgut, por su mayor reabsorción, cedería a la menor tracción. vaciando el contenido hacia el lumen intestinal y no hacia el peritoneo, Las peritonitis plásticas han sido todas mortales, a pesar de resecciones intestinales, ileostomías, etc.

El absceso subfrénico fué secundario a una peritonitis por apendicitis posterior ascendente, en que la primera operación no permitió la extirpación completa del apéndice. (se practicó una apendicectomía retrógrada); su evolución fué favorable.

Las obstrucciones mecánicas por bridas o adherencias post-operatorias son raras. Como podemos ver, seguramente influye en esto, que levantamos precozmente los enfermos. '(Cuadro 2). En los 3 casos fué necesaria la reintervención y la sección de ellas.

\section{GUADRO $\mathrm{N}^{\circ} 2$}

Fueron dados déalta después de un postoperatorio de:

$\begin{array}{cccc}2 \text { dias } & 3 \text { días } & 4 \text { dias } & \text { más de } 4 \\ 44 & 399 & 503 & 904\end{array}$

El volvulus en dos ccasiones fué consecutivo a una peritonitis y sólo una vez lo observamos en una apendicitis crónica reagudizada con áscaris.

Los cuadros hasta aquí enunciados, en realidad tienen poco interés para los pediatràs, por ser complicaciones que podríamos considerarlas como quirúrgicas puras. No sucede lo mismo con las que pasaremos a ver ahora, que tienen ana causa común y se diferencian sólo por su perícdo de evolución. Me refiero a la dilatación gástrica, intestinal e ileoparalítico. La causa exacta de su génesis parece ser múltiple. El shack pre y post-operatorio, el suministro de alimentos, el mal funcionamiento intestiral, los purgantes antes o después de la intervención, el exceso de compresión de las asas intestinales con pinzas durante la operación. la excitación sim- 
pática, la aereofagia y el estado general mismo del enfermo son factores que influyen en forma manifiesta para que estos cuadros se produzcan. Tienen la característica de ser progtesivos, de pasar desapercibidos cuando la dilatación sólo es gástrica, pero que, a medida que avanza, se hace presente por vómitos, decaimiento general, deshidratación. El abdomen, de blando y depresible, presenta primeramente timpanismo alto, que luego abarca todo el abdomen, el cual se hace sensible, díbujando a veces las asas intestinales. El edema comienza por las regiones maleolares o toma el carácter de edema decúbito. El intestino se aprecia muy distendido por el aíre contenido, que contrariamente a lo que se creía, en su mayor porcentaje es de origen externo y sólo una pequeña cantidad proviene de la sangre (alto porcentaje de nitrógeno y bajo en oxígeno). La pared intestinal está exangüe por la compresión de los vasors sanguíneos y línfáticos, con su poder de contracción alterado, fenómeno que se hace más grave cuanto más antigua es la distensión. Pero, el factor más alarmante es el que se manifiesta en la sangre, cuya concentración de proteínas y electrolitos se modifica, lo que repercute sobre el higaxlo y el riñón. Este fenómeno es el que nos explica los fracasos del tratamiento de la parálisis intestinal, por simple reabsorción del gas y del líquido contenido en el intestino, a pesar de acompañarlo de la hidratacjón por fleboclisis. Estos métodos pueden ser suficientes sólo en un comienzo, pero aun ellos, como veremos, van acompañados de fenómenos vasomotores, que no pueden tener su origen simplemente en la distensión y que seguramente se deben a alteraciones, aunque pequeñas, de la concentraciór sanguínea.

Al diagnosticar estos cuadros, hay que saber diferenciarlos de aquéllos producidos por uremia, por trastornos medalares o mecánicos.

Como ya decíamos, el tratamiento de la dilatación gástrica, intestinal o ileo paralítico, exige la colaboración del internista, transfusor, laboratorista, etc. 'Y su pauta de tratamiento sería la siguiente: a todo enfermo, al cual durante el acto operatorio se le comprueba una peritonitis, debe practicársele inmediatamente el vaciamiento gástrico, dejando la sonda durante 6 a 12 horas bajo el más absoluto reposo gástrico e intestinal, agregando, por to tanto, la fleboclisis de suero glucosado y Ringer con sulfa o penicilina, para evitar la deshidratación y combatir la infección. Si se ve que el fenómeno progresa, se comienza a avanzar la sonda suave- 
mente, practicando una proteinemia y hematocrito, para determinar la indicación de plasma o sangre. La cantidad de liquido extraido, a través de la sonda, debe ser medida, para calcular la cantidad de líquido y cloruros que debe recibir $\mathrm{cl}$ enfermo. Después de 48 a 96 boras revisamos lá contractibilidad intestinal, para lo cual se da al enfermo, durante 3 horas, líquido a tomar y luego, inflando el balón, se comienza nuevamente a vaciar el contenido intestinal. Si la cantidad extraída es menor que la suministrada, puede comenzarse a dar líquido a través de la sonda. Las proteínas dadas a través de ella, se reabsorben al principio con mucha dificultad; es por eso que las preferimos por vía endovenosa, constituyendo un valioso aporte el producto llamado Amigen (aminoácidos y polipéptidos), que usado, si bien es cierto, hasta ahora, poco por rlosotros, da espléndidos resultados. Se calculan los aminoácidos a razón de $0,50 \mathrm{gr}$. por $\mathrm{kgr}$. de peso para las 24 horas. Bajo un personal competente y suministrándolos en forma lenta, se ve una recuperación más rápida de la motilidad intestinal y una evolución muy favorable de la peritonitis.

Una vez manifestada la tolerancia del intestino para los líquidos, se puede dar alimentos a través de la sonda o retirar ésta completamente.

Un complemento valioso lo constituye el suministro de pequeñas cantidades de oxígeno, en forma intermitente, a través de la sonda. Parece conseguirse con ello una mayor reabsorción del gas contenido en el intestino. La prostigmina. empleada al príncipio cada 3 horas, $y$ luego cada 6 , es útil. Contraindicación absoluta tiene el uso de la atropina. Desde que seguimos esta técnica, hemos conseguido la recuperación total de los cuadros de la dilatación gástrica e intestinal, después de 24 a 96 horas, y de dos cuadros de ileo-paralítico (4 días). La conducta seguida para esta complicación, debería seguirse también en aquellos cuadros carenciales del niño, que se complican de parálisis, $\sigma$ distensión intestinal y que alteran, por lo tanto, el metabolismo. $\mathrm{La}_{a}$ sonda. Miller Abbott, que para el lactante es excesivamente gruesa, puade ser rcemplazada por una goma delgada y flexible, que se usa vulgarmente en las válvulas de bícicleta.

Las fístulas estercoráceas se han certado espontáneamente en su mayoría; en sólo 2 casos hubo necesidad de resecarlas; una por simple sutura de la pared, por tratarse del ciege. y la otra, por anastomosis laterolateral.

Las neumonías han evolucionado favorablemente, gracias al efecto maravilloso de los sulfas preparados. 